\title{
Features of Vocal Music Art
}

\author{
Yong Lu \\ Hubei Engineering University, Xiaogan Hubei, 432000, China
}

Keywords: Vocal art, Performing arts, Instrumental music, Aesthetics.

\begin{abstract}
Vocal art is a kind of music performance art, which is the art of tone and language formed by the sound of the human body itself. Compared with instrumental art, it has obvious shape. It is by virtue of the description of the language, can more directly and specifically express people's subtle feelings. It has the unique aesthetic characteristics of music performing arts, and it has the unique aesthetic nature which is different from other music performing arts. It plays an important role in the whole society's popularization of vocal music and the improvement of vocal art level. Based on the previous macro research, this article will elaborate the characteristics of vocal art from four aspects with in-depth analysis and cited examples .
\end{abstract}

\section{Introduction}

Vocal music art is one of music performance art, which has common aesthetic features of music performance art as well as unique aesthetic nature different from other music performance art. Just as $\mathrm{Yu}$ Dugang said, "As one of the forms of music art or aesthetics, vocal music has differences from instrumental music art in principle. Regardless of its artistic creation process and artistic expression, its creation composition and artistic effect, its artistic content and form, its type and style or its aesthetic effect and function, it has its features and law." [1] The study on vocal music art theory consists in "revealing the particularity of music art form, thus mastering the essence and law of vocal music art comprehensively." [2]

Features of vocal music art are described in four aspects below.

\section{Comprehensive features}

First, as a discipline, vocal music art mainly uses for reference and applies materials of other relevant disciplines. That is to say, knowledge structure of vocal music art is an organic complex of other relevant disciplines. In terms of singing skills, human physiology, psychology, education, aesthetics and performance are closely related to it. This is different from other music performance art. Except vocal music performance, a main category of music performance is instrumental music performance. Musical instrument science becomes a "discipline" independently. Instrumental music performance personnel can play without the knowledge of "musical instrument science". Vocal music art is almost a synonym of "vocal music science". Human body is an "instrument". The study on physiological structure and functional movement of human body related to vocal music performance becomes an important constituent part of vocal music learning. In terms of meaning communication of vocal music works, singing performance may be conducted as more comprehensively and accurately as possible with common sense of disciplines such as the science of history, aesthetics, performance, linguistics and music work analysis. Then, comprehensiveness is also manifested in the division of vocal music art into performance and singing. Singers should master not only singing skills but also performance skills. 
In this sense, vocal music art requires singers to have rich and comprehensive disciplinary knowledge. Yang Yihe said, "The acceptance of any new information will be included in the original psychological schema of the theme, i.e. information storage, thus producing double effect of 'assimilation' and 'adaptation'. Misunderstandings occurring during reading, i.e. wrong decoding, are caused by the lack of adequate decoding ability of the original psychological schema. By this token, knowledge structure is actually a vital issue." [3] Yang Yihe provided some reference disciplines for the improvement of accomplishment of music performers: "philosophy, general history, music history, music performance art history, music aesthetics, music performance technology, music work analysis technology, music psychology, music physiology, biological motion dynamics, national music, folklore, philology, special, logic, acoustics, education and general literature and art cultivation etc."[4] The quantity and depth of learning of such disciplinary knowledge vary with each individual and cannot be absolutized. However, it shall be extensive as much as possible in case of need.

\section{Intermediary features}

As mentioned above, vocal music art belongs to music performance art, which has common aesthetic features of music performance art as well as significant differences from other music performance. The Record of Music • Music Image Chapter said, "poetry expressing wills; singing manifesting voice; dancing showing appearance; the three originates from heart, then followed by instrument." [5] The Record of Music • Shi Yi Chapter said, "therefore, song is for words; chant. Say it, sing it; when it is inadequate to express with singing, just chant. When it is inadequate to express with words, sigh; when it is inadequate to express with sigh, dance." [6] The Preface to Mao Poetry said, "When emotion is touched in the heart, it will be expressed with words. When it is inadequate to express with words, sigh; when it is inadequate to express with sigh, sing; when it is inadequate to express with singing, dance." [7] Therefore, it is a bridge connecting language and pure music art (especially instrumental performance art).Bridge represents transition. There must be a reason for transition. Different purposes, functions and aesthetic features of vocal music art and language and other music performance art are compared below so as to have deeper understandings of the special charm of vocal music art.

As symbol, daily language has basic functions - practicability and semantic feature. Though it has certain rhyme and rhythm, such rhyme and rhythm are not perceptual styles after rational organization; instead, they have great randomness and spontaneity.

In fact, just as that mentioned in The Record of Music and The Preface to Mao Poetry, daily language and vocal music art have a so-called "words" and "sigh" which might include spoken parts in the art of elocuting and drama. Though they have strong practical effect of semantic feature, their aesthetic nature is greatly improved compared to daily language. Such aesthetic nature reflects the rhyme, mood and rhythmicity of language in cadence. That is to say, their rhyme and rhythm have become organized consciously with certain aesthetic intention. Such consciousness and representation intention have not risen to the height of "good hearing and emotional style" [8]. It still does not take acoustic structure of rhyme and rhythm as main carriers and take aesthetics as the main purpose. Therefore, they need to "continue upgrading" if for the purpose of aesthetics.

Music performance art except vocal music art is collectively called as instrumental performance art. The development of vocal music art should be earlier than that of instrumental art. In terms of the purity of aesthetics, instrumental art should be better. Liu Chenghua said, "The most representative tone quality of western vocal music is undoubtedly the pronunciation in bel canto. The principle of such pronunciation is that a beautified tone with universality far away from daily voice is achieved on the basis of full application of vocal organs and resonance organs with the change of natural state of voice as hub. Such tone is the 'instrumental voice'." [9] This paragraph not only demonstrates the spiritual standard of cultural aesthetics of western music, but also indicates that vocal music art has lower aesthetic purity than instrumental art. Otherwise, why is it "close to instrumental voice"? This 
proves that instrumental performance art moves a step forward on the path of getting away from daily life of people. Though there are such sentences in ancient China as "singing of human is primary and the sound of accompanied instrument is secondary" [10] and "singing is the sound of happiness; string music is no match for wind music; wind music is no match for the voice of human singing" [11], they are for "humanistic thought" in Chinese cultural spirit and just indicate that vocal music art is closer to music art in the daily life of people.

To sum up, from daily words to "chant" and "sigh", to vocal music art, and finally to instrumental art, their aesthetic purity has gradually improved. Vocal music art is playing an important role of connection. Therefore, we define vocal music art circles as an artistic form of "bridge" connecting daily words and instrumental performance art. This statement should be accurate.

\section{Aesthetic and practical features}

Singing of human beings has two functions: practical function and artistic function.

"When music is used for manifesting non-practical aesthetics, thoughts and feelings, it has artistic function. The implementation of artistic function of music is to touch people with the perceptual power of meaningful sound $\cdots$. Perceptual activities of music become one of the best life patterns of people $\cdots$. In terms of creation, performance and appreciation of music works, non-utilitarian artistic purpose is directed at spiritual auditory sense demands. Aesthetics is one of the most important demands. $\cdots$. Meeting aesthetic demands of people is a basic manifestation of artistic function of music." [12]. Vocal music art is one of the art types mostly touched by people in music. Its artistry especially aesthetics is its main perceptual demand.

With the penetration of various media into various aspects of social life, people can see increasingly closer combination between aesthetics and practicability of vocal music art. While using practical function of vocal music art, people pay more and more attention to its aesthetic value. The improvement of aesthetic value can strongly promote its practical function.

\section{Most humanized artistic features}

Vocal music art is regarded as the most humanized music performance art as it is the music performance art closest to life, manifesting life contents most directly and reflecting life spirit besides the widest and deepest participation of people in each link.

\section{Performability}

As discussed above, one of the most important differences between vocal music art and instrumental performance art is that the former is closer to human. There are several reasons:

First, it has double functions of semantic feature and aesthetics. Semantic feature of lyrics (poem) in vocal music performance places people in ordinary conversation and can make them understand to the greatest extent. This is the basic platform required for heart-to-heart communication. Instrumental music performance only involves sound symbol and can only achieve the required purpose with the organization of pitch, value, volume and tone. This is the charm of instrumental performance art. Therefore, the author does not intend to make any judgment here and just indicates the reason why vocal music art is closer to human. Opera is always manifested through singing. Acting is often called as singing. This also reflects the special importance of singing in opera." [13] "Singing contains music and language. The processing of their relationship has great relation with the overall effect of expression of singing.

Second, it emancipates the action of singers to the greatest extent and is good for their performance. Such performance can make people understand to the greatest extent. Expression in eyes, facial expression and action can be random as usual and absolutely lifelike. As instrument is outside the body and hands, feet and eyes have to be considered and parts that can move substantially are restricted; though expression in eyes and facial expression may participate, its disadvantage of 
lacking semantic feature is exposed - corresponding facial expression (if any) cannot be understood and sometimes is even counter-productive.

Semantic feature can make people understand through listening. Unrestricted performance can make people understand by seeing. Rhyme and rhythm of singing provide people with deeper aesthetic feelings. This is the benefit of overall participation of human (singers).

\section{Role}

Besides creating music image and artistic conception, vocal music art also provides people with direct role impression of singers. As is known to all, people in the real life present different identities at different time, in different occasions and under different situations. While playing different roles in life, people have varying thoughts, words and actions. Their tone, pace and actions are different. "Performance" in vocal music art has direct and important relation with thoughts, words and actions of the role.

"When a Chinese person meets a problem which has to be coped with, he will immediately regard himself as a role in a play $\cdots$. If this problem is solved, he will consider himself honored. If it cannot be solved, he will feel embarrassed. If it cannot be solved and becomes worse, he will feel collapsed. If the problem cannot be solved due to the interference or trouble making of any other person, he will say that the person is letting him down. In a word, life is a drama and the world is a theatre in the opinion of Chinese. Therefore, many nouns are universal."[15] Qian Mu said, "the ideal of Chinese in life is generally performed in Chinese drama." [16] This shows the principle that the role of human in life is interlinked to that in performance. While appreciating vocal music performance, audiences have a corresponding role more or less, i.e. comparison with the situation in life. Such comparison and correspondence are important reasons why people are familiar with vocal music art.

\section{Universality}

Vocal music art is a music performance activity generally participated and accepted by people at any time in any region. Due to the demand of people and media transmission, vocal music art activities have been increasingly frequent with unprecedented quantity and quality. Performance sites such as studio and music hall have been established in many regions and colleges. Such sites are boisterous with singing and dancing during holidays or celebration. Vocal music programs have the largest number among performance programs. This can indicate the following: first, there are more practitioners and participants of vocal music art than other music performance art; second, people have higher degree of acceptance for vocal music program than other music programs; third, vocal music art has wider popularity in the society than other music performance art.

In terms of education, it was an auxiliary music course but now becomes a means for improving comprehensive accomplishment. The education of vocal music becomes an important course. There are always a large number of music candidates in college entrance examination, among which candidates in vocal music direction account for a large portion. In the School of Music in colleges and universities, students in many directions of each major must learn vocal music course. Thousands of music graduates cultivated by colleges and universities flow into the society and play a more and more important role in the popularization of vocal music art and the improvement of its level in the whole society.

\section{References}

[1] Yu Dugang: Vocal Music Art Aesthetics, Higher Education Press, May 1993, pp. 4.

[2] Yang Yihe: Principle and Application of Music Performance Art, Anhui Literature and Art Press, October 2002, pp. 34.

[3] Cai Zhongde: Information Notes and Translations of Chinese Music Aesthetics History, People's Music Publishing House, September 2007, pp. 284. 
[4] Chief Editor Zhang Qian: Music Aesthetics Course, Shanghai Music Publishing House, February 2002, pp. 84.

[5] Liu Chenghua: Humanistic Interpretation of Chinese Music, Shanghai Music Publishing House, October 2002, pp. 78.

[6] Selected from The Book of Rites, Cai Zhongde: Information Notes and Translations of Chinese Music Aesthetics History, People's Music Publishing House, September 2007, pp. 364.

[7] Selected from [Tang] Duan Anjie Yuefu Zalu, Xiu Hailin: A Collection of Historical Materials of Ancient Chinese Music, Xi'an World Publishing Corporation, September 9, 2000, pp. 294.

[8] Chief Editor Zhang Qian: Music Aesthetics Course, Shanghai Music Publishing House, February 2002, pp. 56.

[9] Lu Yingkun: On the Opera Art, Beijing Broadcasting Institute September 2002, pp. 3 and 4.

[10]Arthur H·Smith : Chinese Characteristics, Quoted from Pan Guangdan: Study on Blood Relationship of Chinese Actors, Commercial Press, Edition 1941, pp. 13.

[11]Qian Mu: Literary Meaning of Chinese Peking Opera, Collection of Chinese Literary Speech, Bashu Publishing House, Edition 1987, pp. 129. 